\title{
Preventing malaria in international travellers: an evaluation of published English-language guidelines
}

\author{
Merav Kliner ${ }^{1,2^{*}}$, Kristina Poole ${ }^{1}$, David Sinclair ${ }^{2}$ and Paul Garner ${ }^{2}$
}

\begin{abstract}
Background: People intending to travel may seek information on malaria prevention from a range of sources. To ensure the best protection, this information needs to be reliable, up-to-date, consistent, and useful to their decision making. This study appraises current international and national guidelines written in English for malaria prevention in travellers, and whether any recommendations conflict.
\end{abstract}

Methods: We systematically identified national or international English-language guidelines on malaria prevention in travellers to July 2013 using standard and multiple searching methods. We critically appraised guidelines using the AGREE II tool, and report inconsistent recommendations within guidelines.

Results: We identified five sets of English-language guidelines on preventing malaria for travellers. Assessment against AGREE II indicate that all of the guidelines fall short of internationally accepted standards in guideline development: none include a transparent description of methods; only one describes sources of funding or potential conflicts of interest; and only one includes formal presentation of the evidence alongside transparent assessment of the quality of that evidence. There were a number of important discrepancies between guidelines, and some omit information about effectiveness, safety and adverse effects of chemoprophylaxis options.

Conclusions: The methods used for developing guidelines for malaria prevention in travellers lags behind current internationally recognized standards. Healthcare professionals as well as travellers themselves could be better informed if guidelines were more systematic and transparent summaries of the current knowledge on drug interventions in relation to effects, safety, administration and contra-indications.

Keywords: Malaria, Travellers, Chemoprophylaxis, Prevention

\section{Background}

In the UK, approximately 2,000 episodes of malaria are recorded each year in people returning from travel to endemic countries, and travellers still die from malaria [1]. Travellers can reduce their risk of malaria illness by taking antimalarial drugs throughout their time abroad as prophylaxis, and by various non-drug interventions which reduce mosquito bites.

People intending to travel may access information on malaria prevention through on-line resources, by visiting their own doctor, through specialist travel clinics, or

\footnotetext{
* Correspondence: meravkliner@nhs.net

${ }^{1}$ Cheshire and Merseyside Public Health England Centre, 5th Floor, Rail House, Lord Nelson Street, Liverpool L1 1JF, UK

${ }^{2}$ Liverpool School of Tropical Medicine, Pembroke Place, Liverpool L3 5QA, UK
}

\section{Biomed Central}

through various travel operators [2]. To ensure the best protection, this information needs to be reliable, up-todate and based on the best available research evidence. In the UK, health workers will usually follow guidelines developed by Public Health England, or available through on-line travel sites such as the National Travel Health Network and Centre (NaTHNaC). However, many other guidelines are available developed by other national or international bodies.

Travellers to malaria endemic settings require information that enables them, and convinces them, to choose the interventions that are most effective and safe for them. This is likely to involve some quantification of the relative benefits and harms of each intervention. To 
facilitate this, good quality guidelines should present this information in a clear and user-friendly format [3].

In this study, we aim to a) appraise the available national and international English-language guidelines on malaria prevention against international best practice in guideline development, b) evaluate the degree of consistency or conflict between guidelines, and c) consider how well the information facilitates informed decision making.

\section{Methods}

\section{Identification of guidelines}

Two authors (MK, KP) searched independently for international or national guidelines for malaria prevention in travellers using: Google, the websites of major public health bodies from English-speaking non-endemic countries (the UK, USA, Australia, New Zealand, Scotland and Canada), the TRIP database, the National Guideline Clearing House, and pubmed (using the search terms: malaria AND (prevent* OR prophylax*) AND guid* AND travel) for articles published until the end of July 2013. Guidelines limited to malaria prevention in sub-groups (such as children), or in languages other than English, were excluded.

\section{Agree II appraisal of guidelines}

Two authors (MK, KP) independently appraised each identified guideline using the AGREE II guideline appraisal tool [4]. The AGREEII tool appraises guidelines against 23 criteria across six domains; scope and purpose, stakeholder involvement, rigour of development, clarity of presentation, applicability, and editorial independence. Each reviewer first assigned a score between one and seven for each criteria (one being the lowest and seven the highest), and the scores of both reviewers were then combined and converted into a percentage score for each domain.

\section{Agreement between guidelines}

Two authors (MK, KP) independently reviewed each guideline to identify both explicit and implicit recommendations relating to prevention of malaria. Explicit recommendations were classified as those where something was clearly being advised (for example, "Spraying before bedtime, combined with the use of a vaporiser is recommended"). Implicit recommendations were classified as statements where judgements are being made (for example, "Insect repellent applied to clothing is effective for longer than it may be on the skin"). Two reviewers mapped recommendations to a standardised table independently and compared and contrasted them. Discrepancies were addressed through discussion between the two reviewers and where discrepancies could not be resolved, a third reviewer (DS) was consulted. Two reviewers (MK, KP) compared the recommendations made by each of the guidelines to identify any conflicts between sets of guidelines.

\section{Results}

Five guidelines met our inclusion criteria, developed by: the World Health Organization (WHO) [5], the Public Health Agency of Canada (CA) [6], the Hong Kong Centre for Health Protection (HK) [7], the Public Health England advisory committee on malaria prevention (UK) [8] and the Centre for Disease Control (USA) [9].

We excluded an article providing advice for travellers from New Zealand, as it was not official national guidance [10], and although our PUBMED search suggested there may be guidelines from Japan, The Netherlands and Spain, these were unavailable in English. No guidance was identified from Australia or Scotland. A brief summary of these guidelines is outlined in Table 1.

\section{Agree II appraisal of guidelines}

The summary AGREE II scores for each of the five guidelines are shown in Table 2.

\section{Domain 1: Scope and purpose}

All five guidelines covered both drug and non-drug interventions to prevent malaria in travellers, and all aimed to assist clinicians as they advise travellers. The UK and HK guidelines provided the most complete description, clearly outlining the objectives, health issue and target population to which the guidelines apply.

\section{Domain 2: Stakeholder involvement}

All guidelines gave a named list of the individuals who primarily authored the document, although only the UK guidelines stated the roles and responsibilities of these individuals. Three guidelines (HK, USA and WHO) also referred to working groups or external contributors but these were not named. None of the guidelines reported involvement of the target population (travellers).

\section{Domain 3: Rigour of development}

None of the guidelines included a Methods section. None described methods to systematically search for and appraise evidence, or to move from evidence to formulating recommendations. None of the documents described external peer review prior to publication, and only the WHO guideline made reference to a process for future updates.

The Canadian guideline presented the evidence base summarized in GRADE tables. All other guidelines summarized evidence in text form, with variable levels of referencing provided to validate recommendations. USA and WHO guidelines provide no references, HK provide some references and UK guidelines provide a reference for many of the recommendations made. 
Table 1 Brief summary of guidelines

\begin{tabular}{|c|c|c|c|c|c|}
\hline & Canada & Hong Kong & UK & USA & WHO \\
\hline Year & 2009 & 2007 & 2013 & 2013 & 2012 \\
\hline Format & $\begin{array}{l}\text { Stand-alone } \\
\text { guidance }\end{array}$ & $\begin{array}{l}\text { Stand-alone } \\
\text { guidance, two } \\
\text { documents }\end{array}$ & Stand-alone guidance & $\begin{array}{l}\text { Within 'Yellow Book' on } \\
\text { travel health, chapter on } \\
\text { malaria (chapter 3) and } \\
\text { prevention against } \\
\text { mosquitos (chapter 2) }\end{array}$ & $\begin{array}{l}\text { Within 'International travel } \\
\text { and health'; chapter on 'malaria' } \\
\text { and subsection on } \\
\text { 'Insects and other vectors of } \\
\text { disease' }\end{array}$ \\
\hline $\begin{array}{l}\text { Development } \\
\text { team }\end{array}$ & $\begin{array}{l}\text { Committee to } \\
\text { Advise on Tropical } \\
\text { Medicine and } \\
\text { Travel ( } 7 \text { named } \\
\text { individuals) }\end{array}$ & $\begin{array}{l}\text { Working Group on } \\
\text { Malaria Prophylaxis } \\
\text { (5 named authors, } 2 \\
\text { collaborating } \\
\text { groups) }\end{array}$ & $\begin{array}{l}\text { Public Health England } \\
\text { Advisory Committee on } \\
\text { Malaria Prevention in UK } \\
\text { travellers ( } 5 \text { named } \\
\text { authors, } 6 \text { named } \\
\text { contributors }\end{array}$ & $\begin{array}{l}6 \text { named chapter authors, } \\
\text { with wide range of editorial } \\
\text { staff, CDC and external } \\
\text { contributors }\end{array}$ & $\begin{array}{l}2 \text { editors, } 3 \text { assistants and a } \\
\text { wide range of } \mathrm{WHO} \text { and } \\
\text { external personnel }\end{array}$ \\
\hline Scope & $\begin{array}{l}\text { Drug and non-drug } \\
\text { prevention of } \\
\text { malaria in travellers }\end{array}$ & $\begin{array}{l}\text { Drug and non-drug } \\
\text { prevention of } \\
\text { malaria in travellers }\end{array}$ & $\begin{array}{l}\text { Drug and non-drug } \\
\text { prevention of malaria in } \\
\text { travellers }\end{array}$ & $\begin{array}{l}\text { Drug and non-drug preven- } \\
\text { tion of malaria in travellers }\end{array}$ & $\begin{array}{l}\text { Drug and non-drug } \\
\text { prevention of malaria in } \\
\text { travellers }\end{array}$ \\
\hline Length & 90 pages & $\begin{array}{l}\text { Split into two } \\
\text { papers, total } 58 \\
\text { pages }\end{array}$ & 97 pages & $\begin{array}{l}\text { Split into } 2 \text { chapters, total } 22 \\
\text { pages }\end{array}$ & $\begin{array}{l}\text { Split into } 2 \text { chapters, total } 26 \\
\text { pages }\end{array}$ \\
\hline
\end{tabular}

All guidelines discussed the health benefits and side effects of interventions to some extent, although the level of detail, particularly around safety was highly variable. The Canadian and WHO guidelines gave some risk estimates for the potential benefits and harms.

\section{Domain 4: Clarity of presentation}

All of the guidelines presented some clear recommendations that were unambiguous and specific, and clearly identifiable. However, all guidelines also included discussions of options without clear recommendations, or implied recommendations incorporated into the text and without clear signposting. The Canadian guidelines were presented most clearly, listing all explicit recommendations in a table.

\section{Domain 5: Applicability}

None of the guidelines discussed the resource implications of the recommendations, and none described potential barriers or facilitators to implementation. None presented audit criteria. Only the USA guideline presented an outline of the advantages and disadvantages of each drug in a user-friendly table.

\section{Domain 6: Editorial independence}

Only the USA guideline described the sources of funding, and made any reference to potential conflicts of interest among guideline developers. The remaining guidelines said nothing, and therefore scored zero for this domain.

\section{Agreement or disagreement between guidelines a. Drug interventions for malaria prevention}

A summary of the drug recommendations made by each of the guidelines has been presented in Additional file 1. The main areas of conflict and omission are related to information on effectiveness, safety and contraindications:

Table 2 AGREE II scores for guidelines

\begin{tabular}{|c|c|c|c|c|c|}
\hline AGREE II domain & Canada & Hong Kong & UK & USA & WHO \\
\hline Domain 1: Scope and purpose ${ }^{1}$ & $14 \%$ & $72 \%$ & $92 \%$ & $44 \%$ & $50 \%$ \\
\hline Domain 2: Stakeholder involvement ${ }^{2}$ & $17 \%$ & $33 \%$ & $58 \%$ & $39 \%$ & $53 \%$ \\
\hline Domain 3: Rigour of development ${ }^{3}$ & $20 \%$ & $9 \%$ & $14 \%$ & $22 \%$ & $12 \%$ \\
\hline Domain 4: Clarity of presentation ${ }^{4}$ & $72 \%$ & $61 \%$ & $53 \%$ & $47 \%$ & $50 \%$ \\
\hline Domain 5: Applicability ${ }^{5}$ & $4 \%$ & $4 \%$ & $13 \%$ & $13 \%$ & $4 \%$ \\
\hline Domain 6: Editorial independence ${ }^{6}$ & $0 \%$ & $0 \%$ & $0 \%$ & $50 \%$ & $0 \%$ \\
\hline
\end{tabular}

${ }^{1}$ Scope and purpose concerns the overall aim of the guideline, the scope of the questions, and the target audience.

${ }^{2}$ Stakeholder involvement looks at the extent to which the guideline development process included the views of all appropriate stakeholders, including the intended users of the guideline and those affected by the recommendations.

${ }^{3}$ Rigour of development examines the process used to search for, synthesize, and appraise evidence, formulate recommendations, and keep them updated.

${ }^{4}$ Clarity of presentation concerns the general language, structure, and format of the guideline.

${ }^{5}$ Applicability requires adequate consideration of the likely barriers and facilitators to implementation, including resource considerations, and advice or tools to improve uptake and implementation.

${ }^{6}$ Editorial independence concerns the adequate declaration and management of potential conflicts of interest related to the funding body or the guideline group members. 
- All guidelines state that atovaquone-proguanil, doxycycline and mefloquine are effective against chloroquine resistant falciparum malaria. Two guidelines quantify this: the Canadian guidelines state that they are 95\% effective and the UK guidelines state that they are $90 \%$ effective, each referencing different documents.

- The Canadian, Hong Kong and USA guidelines state that atovaquone-proguanil has an excellent safety profile, with only the Canadian guidelines quantifying that $8 \%$ to $15 \%$ of individuals experience nausea, vomiting, abdominal pain or diarrhoea. The guidelines state that the most common side effects are headache and gastrointestinal upsets, but again do not quantify this.

- Although the Canadian guideline outlines that atovaquone-proguanil has an excellent safety profile, it outlines that it should be used in caution in patients with HIV and liver disease. This is not discussed in other guidelines;

- The US guideline states that atovaquone-proguanil cannot be used in children under $5 \mathrm{~kg}$, whereas all other guidelines state $11 \mathrm{~kg}$ as the cut-off;

- All guidelines state that doxycycline may be photosensitising and can lead to a rash, however no guidelines quantify this risk;

- All guidelines state that doxycycline may lead to gastrointestinal upset and oesophageal ulceration, however no guidelines quantify this risk;

- The UK guideline states that doxycycline is contraindicated in children under 12 years, while all other guidelines say 8 years;

- All guidelines state that mefloquine can lead to major neuropsychiatric side effects such as seizure, psychosis and suicidal ideation. The Canadian and WHO guidelines quantify this. Canadian guidelines suggest that 1 in 6,000 to 13,000 have seizure or psychosis; and WHO guidelines suggest severe neuropsychiatric disturbance in 1 in 10,000.

- The Canadian, Hong Kong and USA guidelines state that mefloquine can lead to minor side effects such as nausea, strange vivid dreams, dizziness, mood changes, insomnia, headache and diarrhoea. The UK and WHO guidelines do not mention this. Only the Canadian guideline quantifies this, suggesting that $95 \%$ of people have no or mild, temporary side effects, with 1 in 250 to 500 having mild neuropsychological reactions e.g. anxiety or mood change;

- The US guideline states that mefloquine can be given to all ages, while other guidelines state it cannot be used in children below $5 \mathrm{~kg}$;

- Stand-by treatments is recommended as being valuable in all guidelines, although the USA guidelines provide very little information regarding this.

\section{b. Non-drug interventions for malaria prevention}

A full outline of the non-drug recommendations made by each of the guidelines has been presented in Additional file 2. There is varying levels of consensus between the guidelines, with a number of significant conflicts.

The main conflicts and omissions are that:

- The WHO guidelines states insecticide-treated clothing lasts longer than skin applied insecticide, whereas UK guidelines states the opposite. Other guidelines provide no recommendations regarding this;

- Concentrations of DEET recommended in children vary from $10 \%$ (CA, HK) to $50 \%$ (UK), and in adults vary from $35 \%$ (CA, HK) to $50 \%$ (UK, USA) in adults. WHO guidelines state that DEET should be used according to manufacturers' recommendations;

- The Canadian and WHO guidelines state that DEET can be used at any age, while the UK and USA guidelines state it should be restricted to children over the age of 2 months. Hong Kong guidelines do not provide recommendations on age limits of DEET;

- The WHO guidelines state that no other protection is required if a hotel is air-conditioned. The UK and USA guidelines imply that malaria transmission is reduced in air-conditioned rooms, and the Canadian and Hong Kong guideline do not provide recommendations on air-conditioning;

- Light covering clothing is recommended by Canada and Hong Kong, while the UK guidelines state this is not effective. USA and WHO guidelines do not provide recommendations on the use of light covered clothing.

\section{Discussion}

Appraisal of the five guidelines using the AGREE II tool indicates that all of the English guidelines surveyed (from national bodies and international bodies) fall short of internationally accepted standards in guideline development. None include a transparent description of methods used, only one describes sources of funding and potential conflicts of interest, and only one includes formal presentation of the evidence alongside transparent assessments of the quality of that evidence. There were a number of important discrepancies between guidelines; and some omit information about effectiveness, safety and adverse effects of chemoprophylaxis options.

Moving from research evidence to healthcare recommendations is not straightforward. High quality evidence that an intervention is effective does not automatically lead to a strong recommendation to implement it, and 
low quality evidence does not preclude a positive recommendation [11]. The process instead involves a series of judgements by the guideline panel, and may take into account the importance of the condition, the applicability of the evidence to the population group, and cost. These judgements are influenced by the values and preferences of the guideline developers, and consequently it is not unexpected that different guidelines developed by different teams will have discrepancies and inconsistencies as highlighted in this paper. More problematic however, is the fact that in most of these guidelines it is unclear what evidence was reviewed, what the strengths and weaknesses of that evidence was, or the basis of the judgements may be the panels.

A second clear deficiency common across guidelines was the lack of user-friendly resources for implementation. Although most guidelines stated that they should be used by healthcare workers and travellers to identify the most suitable interventions for individuals, most did not provide adequate information to help these decisions between different strategies, and quantified estimates of the proportion of people who would be likely to benefit or be harmed by an intervention were rarely given. This was particularly true of drug interventions where side effects are often one of the most important factor influencing choice $[12,13]$. Therefore, they did not give adequate information about when chemoprophylaxis should be used, and if so, which drug should be given. Shared decision making between healthcare workers and patients may be beneficial where evidence is scarce or conflicting and can be encouraged by adapting guidelines to including information for healthcare workers on how to discuss options with patients, and ensuring that the guidelines are accessible to patients such as through patient support tools $[14,15]$.

In addition there were a number of inconsistencies or discrepancies between guidelines. Most were omissions of information, but some reflected different or conflicting recommendations. Identifying these may suggest this is where the evidence is weak or limited, and expert judgment alone has been the main driver of the recommendation. Being clear and transparent about the presence or absence of high quality evidence behind a recommendation helps identify priority research questions, and stimulate a genuinely useful research agenda.

One limitation of this study is that we only included English-language guidelines. Italian guidelines, published as a summary in English after the literature search was conducted for this paper, outlines that national and internationals guidelines have moved in a varying degree away from routinely recommending chemoprophylaxis to a greater use of a wide range of preventative methods [16]. There may be a difference in recommendations between English-language and non-English-language guidelines and using these methods in a cross-language comparison may provide help in assuring guideline quality and standardising recommendations for preventing malaria.

\section{Conclusions}

We evaluated five sets of guidelines written in English on the prevention of malaria for travellers. Guidelines had a number of omissions and conflicts, and were not clearly based on evidence. Healthcare professionals and travellers would benefit from consistent, easy to use guidelines, based clearly on evidence, and outlining current knowledge on effectiveness of interventions, safety, administration and contra-indications.

\section{Additional files}

Additional file 1: Consensus between guidelines for drug interventions.

Additional file 2: Consensus between guidelines for non-drug interventions.

Abbreviations

CA: Canada; HK: Hong Kong; WHO: World Health Organisation.

\section{Competing interests}

Public Health England has employed both MK and KP, and PG has an honorary contract with $\mathrm{PHE}$, whose guidelines are included in the study. DS and PG are members of the WHO Technical Expert Group on Malaria Chemotherapy. Although this group has considered malaria prophylaxis in travellers, no recommendations have yet been made. DS and PG are the co-ordinating editors of the Cochrane Infectious Diseases Group, whose brief includes supporting and publishing systematic reviews in malaria relevant to travellers.

\section{Authors' contributions}

MK, DS, and PG conceived and designed the project. MK searched the literature and extracted and analysed data, and drafted the manuscript. KP searched the literature and extracted and analysed data and revised the manuscript critically for important intellectual content. DS and PG revised the manuscript critically for important intellectual content. All authors read and approved the final manuscript.

\section{Acknowledgements}

PG and DS are supported by the Effective Health Care Research Consortium, which is funded by UK aid from the UK Government Department for International Development.

Received: 4 June 2014 Accepted: 21 October 2014

Published: 3 November 2014

\section{References}

1. Health Protection Agency: Malaria imported into the United Kingdom in 2011: implications for those advising travellers. Health Prot Rep 2012, 6(17):3-6.

2. Bazaz R, Green E, Green ST: Quality of malaria information provided on Internet travel operator websites. Travel Med Infect Dis 2010, 8:285-291.

3. National Institute for Health and Care Excellence. About clinical guidelines. http://www.nice.org.uk/aboutnice/whatwedo/aboutclinicalguidelines/ about_clinical_guidelines.jsp.

4. AGREE II: http://www.agreetrust.org/.

5. World Health Organisation: International travel and health. Geneva: World Health Organisation; 2012.

6. Public Health Agency of Canada: Canadian Recommendations for the Prevention and Treatment of Malaria Among International Travellers. CCDR 2008, 34(S3):1-45. 
7. Centre for Health Protection: Scientific Committee on Vector-borne Diseases: Guidelines on malaria chemoprophylaxis for travellers from Hong Kong. Hong Kong: Department of Health Protection, Department of Health, Hong Kong Special Administrative Region, Hong Kong; 2007.

8. Public Health England: Guidelines for malaria prevention in travellers from the UK. Public Health England 2013. Accessed at https://www.gov.uk/ government/publications/malaria-prevention-guidelines-for-travellers-fromthe-uk on 27/10/14, Published 29/7/14.

9. Arguin PM, Tan KR: Malaria. In Yellow Book, Centers for Disease Control and Prevention (CDC). Atlanta: Georgia; 2013.

10. BPAC NZ: Providing medical advice to travellers. BPJ 2011, 41:30-39.

11. Guyatt GH, Oxman AD, Kunz R, Falck-Ytter Y, Vist GE, Liberati A,

Schünemann HJ, GRADE Working Group: Rating quality of evidence and strength of recommendations: Going from evidence to recommendations. BMJ 2008, 336:1049-1051.

12. Akhtar S, Mukherjee S: Chloroquine-induced mania. Int J Psychiatry Med 1993, 23:349-356.

13. Toovey S: Mefloquine neurotoxicity: a literature review. Travel Med Infect Dis 2009, 7:2-6.

14. O'Connor A: Using decision aids to help patients navigate the 'grey zone' of medical decision making. CMAJ 2007, 176:1597-1598.

15. van der Weijden T, Pieterse AH, Koelewijn-van Loon MS, Knaapen L, Légaré F, Boivin A: How can clinical practice guidelines be adapted to facilitate shared decision making? A qualitative key-informant study. BMJ Qual Saf 2013, 22:855-863.

16. Calleri G, Castelli F, El Hamad I, Gobbi F, Matteelli A, Napoletano G, Romi R, Rossanese A: New Italian guidelines for malaria prophylaxis in travellers to endemic areas. Infection 2014, 42(1):239-250. doi:10.1007/s15010-0130563-3. Epub 2013 Dec 18.

doi:10.1186/1471-2458-14-1129

Cite this article as: Kliner et al.: Preventing malaria in international

travellers: an evaluation of published English-language guidelines. BMC Public Health 2014 14:1129.

\section{Submit your next manuscript to BioMed Central and take full advantage of:}

- Convenient online submission

- Thorough peer review

- No space constraints or color figure charges

- Immediate publication on acceptance

- Inclusion in PubMed, CAS, Scopus and Google Scholar

- Research which is freely available for redistribution 